\title{
A Systemic Model Proposed for the Management of Local Environmental Education, Awareness and Protection: A Case Study
}

\author{
Evangelos C. Papakitsos ${ }^{1} \&$ Anastasios Mavrakis ${ }^{2}$ \\ ${ }^{1}$ Center for Counseling \& Career Guidance of Elefsina, Western Attica, Greece \\ ${ }^{2}$ Environmental Education, Secondary Education Directorate of Western Attica, Greece \\ Correspondence: Evangelos C. Papakitsos, Dim. Ralli 28, Athens, GR 11144, Greece. E-mail: papakitsev@sch.gr
}

Received: June 2, 2018; Accepted: June 27, 2018; Published: July 31, 2018

\begin{abstract}
The present study proposes a systemic model for the operation of small local environmental centers, as a key factor for the implementation of environmental policies that are close to local communities. The presentation and analysis of the required activities of local environmental organizations and the duties of their staff highlights their complex and demanding multidisciplinary character. The consequent necessity to optimize their operation, in order to respond more holistically and effectively to their complex mission, has been the motivation for the present study, proposing a planned operation based on techniques from Systems Science.
\end{abstract}

Keywords: environmental science, environmental awareness, Systems Inquiry, Systems Methodology

\section{Introduction}

The environmental science concerns the study and applications of protecting the natural environment on governmental, organizational or individual levels, for the benefit of both the people and the environment. The natural environment is endangered because of various human activities, including overpopulation, overconsumption and pressure on natural resources, extensive usage of chemicals etc. Since the 1960s, a gradually increasing environmental movement caused awareness of the various environmental issues (Lytle, 2007; Murphy, 2005) that eventually forced governments and organizations to recognize the problem and proceed both to participate in international environmental agreements (Mitchell, 2003) and to establish a relevant national legislation or practices for environmental protection (Blackman, 2008; Karamanos, 2010). From these latter practices, it becomes indirectly obvious that without the environmental awareness of local communities any protective policies and technologies will be less effective. Yet, the issues of environmental science are so many and diverse that require a multidisciplinary approach, on behalf of the local environmental organizations. A typical example of this approach, focusing on developing and retaining environmental awareness to local communities, is the Centers for Environmental Education (henceforth CEE), which are local organizations of the Hellenic Ministry of Education, Research \& Religious Affairs (henceforth HMERRA: www.minedu.gov.gr). Their mission is not restricted to the local educational communities, but also include the broader local societies (HMERRA, 2011). According to the relevant legislation that determines the mission of CEEs (HMERRA, 2016, pp. 23-25), their topics include a wide range of subjects, divided into 15 thematic axes that will be presented in the next subsection.

\subsection{Environmental Topics}

The topics of CEE are practically identical to the topics of environmental science, in general, with the exception of some of them that obviously concern specifically an educational context. Each thematic axis (see 1.1.1-15) includes a number of topics between two to eight.

\subsubsection{Sustainable School - Courtyard of School}

1) Energy sources in school and the school community's behavior to save energy.

2) Initiatives to improve the quality of the relationships between school community members and the environment at school.

3) Marking for cleanliness.

4) Care and responsibility for the courtyard and the classroom.

5) Envisioning the school of the future. 


\subsubsection{Sustainable Residence}

1) Design of buildings, settlements and cities within the planet's carrying capacity.

2) Bio-climatic architecture.

3) Material safety and hazards, e.g., of furniture, oil paints etc.

1.1.3 Energy Issues: Ecological/Energy footprint at school and at home

1) Individual daily transports.

2) Transportations.

3) Alternative forms of energy for heating/cooling.

4) What do we spend on energy?

1.1.4 Local Environment (home, school, community)

1) Acquaintance with the local ecosystem.

2) Waste management in the city I live in.

3) Personal and collective responsibility for protecting the flora in our immediate environment.

4) Activities and everyday habits that affect the bearing capacity of gorges, forests and beaches.

1.1.5 Free Spaces: Exploitation - Configuration - Protection

1) Playgrounds - sports and entertainment venues.

2) Suitability of premises in terms of cleanliness, materials, care, voluntary participation to their control and maintenance.

3) Adopting and protecting a grove or a beach of our country.

1.1.6 Conservation and Protection of Urban and Suburban Green Areas

1) Change of land use.

2) Urbanism and unemployment.

3) Ecological burden.

4) The importance of Land Registry in Land Use Management.

1.1.7 Biotechnological Applications and the Environment

1) Genetically Modified Organisms (GMOs): Production of food from genetically modified organisms; hybrids, wild plant varieties, genetically modified plants; effects of GMOs on the environment, health, economy and society.

2) Traditional local crops and their relationship to the local economy and the environment.

1.1.8 Natural Resources Management

1) Intensive forms of exploitation of natural resources.

2) Forests, deforestation, soil erosion.

3) Water resources.

4) Agriculture, livestock farming, overexploitation; the relationship between Economy and the protection of the local environment; the emergence of exemplary local economically-friendly land uses with respect to the environment.

1.1.9 The Concept of Conservation of the Natural Environment

1) Ecosystems: structure and operation of terrestrial and aquatic ecosystems.

2) Biodiversity, threatened species and protected areas.

\subsubsection{The Concept of Environmental Degradation}

1) Atmosphere, air pollution, greenhouse effect, ozone hole.

2) Water pollution.

3) Soil pollution.

4) Radioactive pollution. 
5) Waste and waste management.

\subsubsection{Environmental Risks}

1) Climate changes.

2) Natural disasters and human intervention.

3) Environment and war.

\subsubsection{Space Organization and Use}

1) Urban environments, urban development, uses, urban and suburban green, road networks, noise pollution, school and indoor environment.

2) Residential development, public space and the environment.

3) Natural environment, space planning, rural development, tourism, alternative tourism and ecotourism, area adoptions.

4) Environment and monuments, archaeological and historical sites.

5) Landscape and habitation, degradation of the landscape.

6) Geological monuments and monuments of nature.

\subsubsection{Anthropogenic Environment: Parameters \& Degradation}

1) Environment and communication, paths - natural routes, transportation.

2) Environment and History: local History, movement History, natural History, History of towns and rural facilities, natural elements, Mythology, Folklore.

3) The environment as a source of inspiration and a forum for dialogue: environment and Arts.

4) The environment as an exhibition: Museums of natural sciences and technology, natural history, collections, exhibits, environmental data in collections, permanent and periodical exhibitions of museums.

5) The environment as a narration: Nature and environmental issues in literature.

6) Environment, perceptions and ideas: Nature and Religion, Environmental Ethics, Democracy, environmental actions and environmental consciousness, Consumerism and the Environment.

7) The environment as the meeting-place of Cultures - Intercultural references.

\subsubsection{Quality of Life}

1) Suitability-risk of materials and structures.

2) Safety at school and at home in relation to objects.

3) Environmentally friendly materials - ways of precaution.

4) Industrial pollution, agricultural pollution.

5) Heavy metals, insecticides, pesticides, bioaccumulation.

6) Solar radiation, electromagnetic radiation.

7) Noise pollution, sound volume, noise map.

8) Hidden pollution: sick buildings, indoor pollution, combustion systems, smoking, building materials, radioactive radon, cleaning materials.

\subsubsection{Human Rights - Democracy}

1) Problems of poverty and illiteracy.

2) Democratic rights, citizens' and children's rights.

3) Social exclusion, equal opportunities, gender equality, racism, xenophobia etc.

\subsection{Necessity for Multidisciplinarity}

The scientific diversity of the afore-mentioned topics (including natural and social sciences, Arts and humanities and technology), is more than obvious and highlights the urgent need for a rational planning of the functions of CEEs and any other environmental organization. This kind of planning should take into account the multidisciplinary character and tasks of an environmental organization, facilitating an appropriate allocation of duties to its members, so as the mission of the organization to be best served. For this purpose, Systems Science 
has to offer useful methods and conceptual tools.

\section{Method}

A system is defined as a complex set of elements, characterized by their properties, relationships and processes, the latter transforming properties and relationships. In a closed system, these elements interact only with each other. In an open system, they interact with their environment. The systemic study of natural phenomena (Systems Science) originates from the classical work of Bertalanffy (1968). This idea was later applied to social phenomena, as well (Laszlo \& Krippner, 1998; Luhmann, 1995; Parsons, 1977), thus defining the two major categories of general systems:

- the natural systems, being popular in Physics, Chemistry, Biology and Mathematics;

- the social systems, alias systems of human activity (Stichweh, 2011).

Therefore, either natural or social phenomena are considered as systems, described by equivalent mathematical models (Heylighen \& Joslyn, 1992). Environmental protection comprises both, as previously demonstrated (see subsection 1.1). In this respect, Systems Inquiry is perhaps the most comprehensive conceptual framework for the study of systems (Papakitsos et al., 2017b).

\subsection{Systems Inquiry}

Systems Inquiry includes three cognitive areas: Systems Philosophy, Systems Theory and Systems Methodology (Bánáthy, 1997), the latter being directly related to applications. Specifically:

- The issues of systems' implementation in the study of both theoretical and practical problems are explored by Systems Philosophy, in more general terms.

- The principles and models of description of the phenomena are explored by Systems Theory in an interdisciplinary way, regardless of their nature or scale of existence (Heylighen \& Joslyn, 1992). This is the oldest area historically, which firstly appeared as General Systems Theory (henceforth GST), linked to Cybernetics as defined by Wiener (1948).

- The discovery of methods, models and techniques for the study of complex systems and the methods of knowledge production for systems are explored by Systems Methodology (Banathy \& Jenlink, 2001).

Systems Methodology includes a variety of conceptual techniques, such as the cognitive maps, that provide a conceptual representation of a particular natural or social environment (Laszlo et al., 1993). In this case, such a conceptual technique, called Organizational Method for Analyzing Systems (henceforth OMAS-III) (Papakitsos, 2013), is suggested and applied herein for environmental planning and studying purposes.

\subsection{Conceptual Technique}

OMAS-III originates from the evolution of two previous popular techniques in Information Systems (Ross, 1977; Grover \& Kettinger, 2000). It has been developed as a conceptual technique for the study and description of general systems. Furthermore, it is combined with concepts of human communication models (Lasswell, 1991), in order to facilitate the application of Systems Inquiry for the study of general systems. OMAS-III has been already proposed and/or used in a large number of applications, mainly in educational context (Papakitsos et al., 2017a).

According to the descriptive model of OMAS-III (Figure 1), the defining elements of a system are seven. These elements identify the issues of (Papakitsos, 2013, p. 180):

- "causality", dealing with the purposes of the system;

- "outcomes", describing the results ("output") of its functions;

- "means", describing the input of the system;

- "rules", defining natural conditions, regulations or legislation that dictates the functions of the system;

- "people", who play a monitoring role;

- "place", defining spatial aspects of the system;

- "time", defining temporal aspects of the system.

These concepts have been applied for modelling an environmental organization, in terms of functions, tasks and activities, considering a localized multidisciplinary context. 


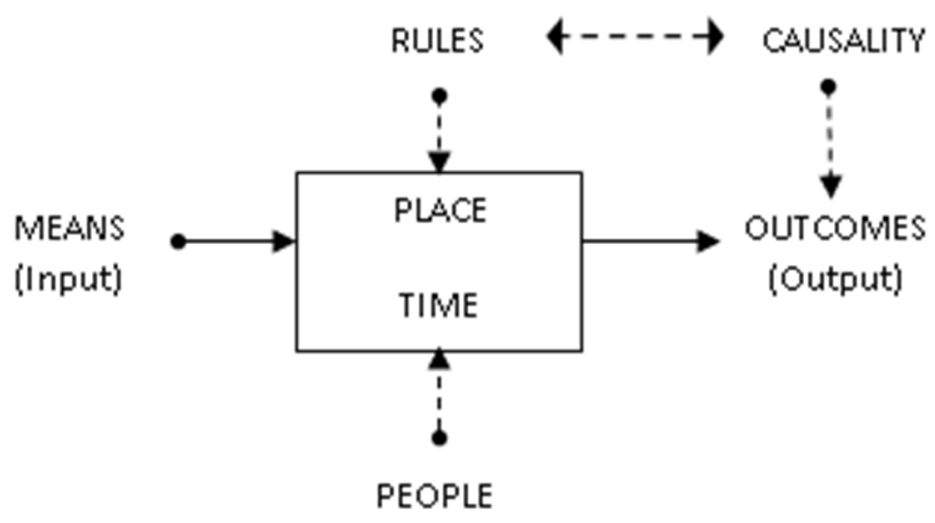

Figure 1. The basic block diagram of OMAS-III

\section{Results}

The existence of a local environmental center, being part of a larger regional, national or international organization, may have three specific goals as a system (systemic "causality") in a holistic manner:

- To monitor the condition of the local environment (systemic "place" and "time");

- to propose actions and solutions for the protection, restoration and development of the local environment (systemic "outcomes" and "rules");

- to contribute to the environmental awareness of the local communities (systemic "people"), through educational and informative activities that should sensitize both the general public and the local authorities.

The usually small size and limited resources ("means") of such a local environmental center makes the necessity of its optimum structure even more imperative. The following description for the accomplishment of the aforementioned goals will be presented according to the classification of OMAS-III, in two categories of the environmental organization's features: thematic fields (see subsection 3.1) and personnel duties (see subsection $3.2)$.

\subsection{Thematic Fields}

The proposed systemic classification of thematic fields differs from the one presented previously (see subsection 1.1), as we may observe that the previous one includes thematic axes (e.g., see 1.1.3-4, 1.1.8, 1.1.12) with topics scattered or incompletely covered (e.g., see 1.1.6), according to the concepts of systems taxonomy. The herein classification of thematic fields is based on five systemic elements, according to OMAS-III (see subsection 2.2).

\subsubsection{Natural Field}

The natural field (systemic "place") regards the presentation and description of the local natural environment (the local ecosystem). It includes the natural resources (e.g., forests, flora and fauna), the geophysical relief (mountains, valleys etc.), wetlands (springs, rivers, lakes and lagoons), protected areas (land and marine parks), the coastline, sea, atmosphere, weather conditions etc. (Note 1).

\subsubsection{Social Field}

The social field (systemic "people") regards the presentation and description of residential areas, land use, social conditions (e.g., unemployment) and social behaviors (e.g., the degree of environmental sensitization and the daily habits/practices) that affect the natural environment (Note 2).

\subsubsection{Technological Field}

The technological field (systemic "means") regards the presentation and description of the methods of production and consumption-use of products, services and energy, how they affect (positively or negatively) the natural and social environment, along with the associated protection and restoration actions required (Note 3).

\subsubsection{Institutional Field}

The institutional field (systemic "rules") regards the presentation and description of the national legislation on environmental protection, international treaties (such as the Kyoto Protocol) and international organizations that are active in protecting the environment and biodiversity (e.g., Greenpeace, WWF etc.) (Note 4). 


\subsubsection{Communicational Field}

The communicational field (systemic "outcome") regards (partially in this particular occasion) the related activities to the last goal of the system, namely, the contribution of the local environmental center to the environmental awareness of the local community, through educational and informative activities that should sensitize both the general public and the local authorities. In this respect, it is important to emphasize the role of sustainable development for the protection of the local environment.

\subsection{Personnel Duties}

Ideally for staffing a small local environmental center, one expert would be required for each thematic field (see subsection 3.1). Furthermore, each expert should be assigned an additional administrative duty (Figure 2), practically typical of any organization, which will be systemically classified and presented once again according to OMAS-III (Papakitsos, 2013, p. 186-187).

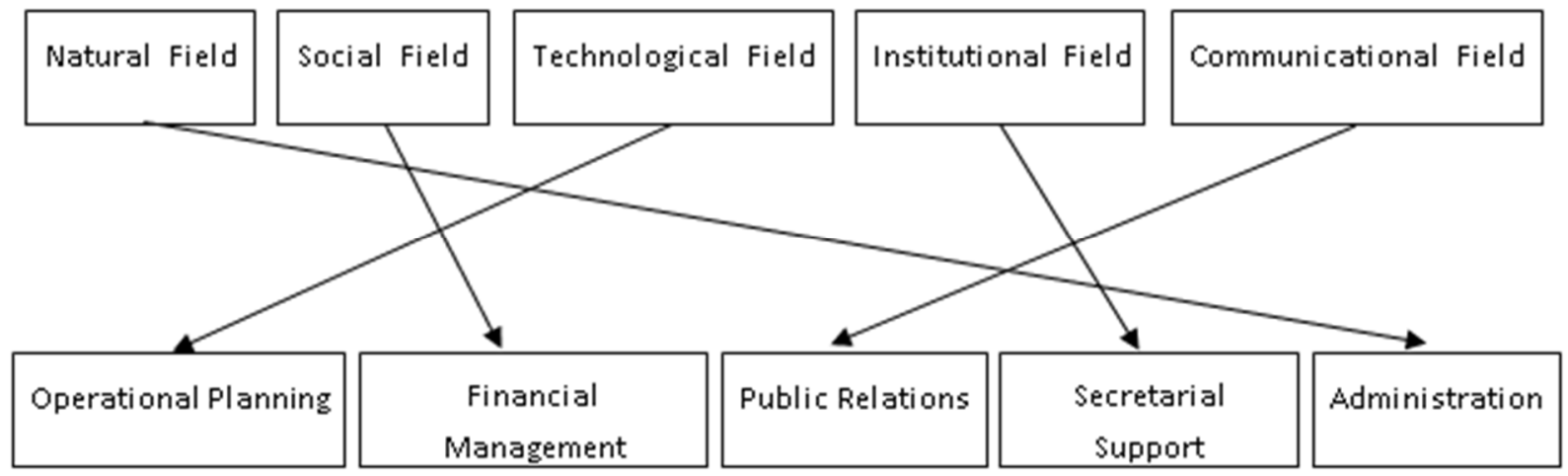

Figure 2. Matching between Thematic Fields and Personnel Duties

\subsubsection{Operational Planning}

In operational planning, the local environmental issues are considered and dealt with, namely, natural attractions, environmental problems and protective actions. This duty can be best assigned to a qualified environmental engineer, expert in the technological field (see 3.1.3), due to the need for submitting protection and restoration proposals.

\subsubsection{Financial Management}

The financial management and maintenance of the infrastructure can be assigned to a scientist, specialized in environmental economy, sustainable development and/or sociology, also expert in the social field (see 3.1.2).

\subsubsection{Public Relations}

Public relations regard the cooperation and contacts of the local environmental center with national and international educational, scientific and environmental organizations, both private and non-governmental, as well as public authorities and the local community, obviously by an expert in the communicational field (see 3.1.5).

\subsubsection{Secretarial Support}

The secretarial support deals with the management of correspondence, the classification and updating of all kinds of documents, either in printed or digital form (archives and database). This particular duty can be assigned to the expert in institutional field (see 3.1.4), who may have a good idea not only of the kinds of documents but also of their content.

\subsubsection{Administration}

Last but not least, the coordinator of the entire function of the local environmental center has to be an expert in the natural field (see 3.1.1), for having a good/overall picture of the area, being also and necessarily specialized in human resources management, to deal effectively with the internal relationships of the team members.

\subsection{Discussion}

Regarding the rational relationship and continuity of the previous thematic fields (see subsection 3.1):

- The knowledge of natural field/environment (see 3.1.1) is a prerequisite for analyzing the impact of the social field/environment (see 3.1.2) on the first. 
- Knowing the social field/environment (see 3.1.2) is a prerequisite for analyzing how technology (see 3.1.3) affects the two previous fields/environments.

- The knowledge of technologies used (see 3.1.3) is a prerequisite for assessing the suitability and adequacy of the institutional framework (see 3.1.4) to protect the environment.

- Finally, the knowledge of the first four thematic fields (see 3.1.1-4) is a prerequisite for the development of relevant awareness programs and campaigns (see 3.1.5).

The above composition of thematic fields (see subsection 3.1) and personnel duties (see subsection 3.2) creates an optimum organization for the staffing and operation of a small local environmental center, by at least five team members. This systemic organization can theoretically cover the full range of environmental activities, since each team member is responsible for a specific thematic field and a group of operational duties, so that no team member is disproportionately charged with workload compared to another.

\section{Conclusion}

Small local environmental centers (like the CEEs in the Greek educational context) may become a key factor for the protection of the local environment. By having presented the issues and tasks of these organizations, their complex and demanding multidisciplinary character has been highlighted. Further quantitative research on their activities may demonstrate their contribution to the local environmental education, awareness and protection. In this respect, a typical case is the CEE of Elefsina city (Western Attica, Greece) that conducts environmental education seminars for approximately the $5 \%$ of the local pupils' population annually.

The prospect of an optimum planning of the operation of local environmental centers, in order to respond more effectively to their complex mission, has been the herein motivation to formulate proposals for their structure and tasks, based on Systems Science techniques. For this purpose, the application of Systems Inquiry has been suggested, which is the most complete theoretical framework of Systems Science. Being the applied cognitive area of Systems Inquiry, Systems Methodology provides powerful conceptual tools, such as OMAS-III, for organizing the environmental protection activities and the assigning of tasks among the members of the local environmental center, towards a qualitative and holistic upgrading of their functions.

\section{Acknowledgments}

The authors would like to thank the reviewers of this journal for their suggestions that improved the presentation of the herein discussed topic.

\section{References}

Bánáthy, B. H. (1997). The evolution of systems inquiry. Systems, 2(1), Techn. Univ. Wroclaw, Poland.

Banathy, B. H., \& Jenlink, P. M. (2001). Systems Inquiry and its Application in Education. In D. H. Jonassen \& J. C. Belland (Eds.), Handbook of Research for Educational Communications and Technology: I - Foundations for Research in Educational Communications and Technology. Bloomington, IN: Association for Educational Communications and Technology. Retrieved from https://www.researchgate.net/publication/255658947_SYSTEMS_INQUIRY_AND_ITS_APPLICATION_I N_EDUCATION.

Bertalanffy, von L. (1968). General system theory: Essays on its foundation and development (rev. ed.). New York: George Braziller.

Blackman, A. (2008). Can Voluntary Environmental Regulation Work in Developing Countries? Lessons from Case Studies. Policy Studies Journal, 36(1), 119-141. https://doi.org/10.1111/j.1541-0072.2008.00249.x

Grover, V., \& Kettinger, W. J. (2000). Process Think: Winning Perspectives for Business Change in the Information Age. IGI Global. https://doi.org/10.4018/978-1-878289-68-1

Heylighen, F., \& Joslyn, C. (1992). Systems Theory. In F. Heylighen, C. Joslyn \& V. Turchin (Eds.), Principia Cybernetica Web. Brussels: Principia Cybernetica.

HMERRA. (2011). Staffing Procedures and Tasks of Teachers in the Centers for Environmental Education (CEE). Protocol No 83691/G7/22-07-2011: Government Gazette 1981, Issue B, 7-9-2011 (in Greek).

HMERRA. (2016). Design and Implementation of School Activities Programs (Environmental Education, Health Education, Cultural Issues), Career Education and European Programmes (Erasmus+, eTwinning, etc.) for the School Year 2016-2017. Directorate General for Primary and Secondary Education: Protocol No 170596 / GD4 / 13-10-2016 (in Greek). 
Karamanos, P. (2010).Voluntary Environmental Agreements: Evolution and Definition of a New Environmental Policy Approach. Journal of Environmental Planning and Management, 44(1), 67-84. https://doi.org/10.1080/09640560124364

Lasswell, D. H. (1991). The structure and functioning of communication in society. In K. Livieratos \& T. Frangoulis (eds.), The message of media, The explosion of mass communication (pp. 65-83). Athens: Alexandria (in Greek).

Laszlo, A., \& Krippner, S. (1998). Systems Theories: Their Origins, Foundations, and Development. In J. S. Jordan (Ed.), Systems Theories and A Priori Aspects of Perception (Ch. 3, pp. 47-74). Amsterdam: Elsevier Science. https://doi.org/10.1016/S0166-4115(98)80017-4

Laszlo, E., \& Masulli, I. (1993) with Artigiani, R., \& Csányi, V. (Eds.). The evolution of cognitive maps: New paradigms for the twenty-first century. New York: Gordon \& Breach.

Luhmann, N. (1995). Social Systems. Stanford, CA: Stanford University Press.

Lytle, M. H. (2007). The Gentle Subversive: Rachel Carson, Silent Spring, and the Rise of the Environmental Movement. New York: Oxford University Press.

Mitchell, R. B. (2003). International Environmental Agreements: A Survey of Their Features, Formation, and Effects. Annual Review of Environment and Resources, 28, 429-461. https://doi.org/10.1146/annurev.energy.28.050302.105603

Murphy, P. C. (2005). What A Book Can Do: The Publication and Reception of Silent Spring. University of Massachusetts Press.

Papakitsos, E. (2013). The Systemic Modeling via Military Practice at the Service of any Operational Planning. International Journal of Academic Research in Business and Social Science, 3(9), 176-190. http://dx.doi.org/10.6007/IJARBSS/v3-i9/200

Papakitsos, E. C., Foulidi, X., Vartelatou, S., \& Karakiozis, K. (2017a). The contribution of Systems Science to planning in local educational administration. European Journal of Education Studies, 3(3), 1-11. https://doi.org/10.5281/zenodo.265909

Papakitsos, E. C., Karakiozis, K., \& Foulidi, X. (2017b). Systemic methodology for inclusive education policies in areas with acute social problems. European Journal of Alternative Education Studies, 2(1), 32-47. https://doi.org/10.5281/zenodo.345186

Parsons, T. (1977). Social Systems and the Evolution of Action Theory. New York: Free Press.

Ross, D. T. (1977). Structured Analysis: A Language for Communicating Ideas. IEEE Trans. Software Engineering, January 1977, 16-34. https://doi.org/10.1109/TSE.1977.229900

Stichweh, R. (2011). Systems Theory. In B. Badie et al. (eds.), International Encyclopedia of Political Science. New York: Sage. https://doi.org/10.4135/9781412959636.n597

Wiener, N. (1948). Cybernetics: or Control and Communication in the Animal and the Machine. Cambridge, MA: MIT-Press.

\section{Notes}

Note 1. Previously corresponding to: 1.1 .4 , No $1 ; 1.1 .8$, No $2-3 ; 1.1 .9 ; 1.1 .12$, No 6 .

Note 2 . Previously corresponding to: $1.1 .1 ; 1.1 .3$, No $1 ; 1.1 .3$, No $4 ; 1.1 .4$, No $2-4 ; 1.1 .5 ; 1.1 .6$, No $1-3 ; 1.1 .8$, No $1 ; 1.1 .8$, No $4 ; 1.1 .11 ; 1.1 .12$, No $1-5 ; 1.1 .13 ; 1.1 .15$.

Note 3 . Previously corresponding to: $1.1 .2 ; 1.1 .3$, No $2-3 ; 1.1 .7 ; 1.1 .10 ; 1.1 .14$

Note 4. Previously corresponding to: 1.1 .6 , No 4.

\section{Copyrights}

Copyright for this article is retained by the author(s), with first publication rights granted to the journal.

This is an open-access article distributed under the terms and conditions of the Creative Commons Attribution license (http://creativecommons.org/licenses/by/4.0/). 